\title{
The Bacon Chow study: effect of nutritional supplementation on maternal weight and skinfold thicknesses during pregnancy and lactation
}

\author{
BY LINDA S. ADAIR \\ Department of Anthropology, Rice University, Houston, Texas 77251, USA \\ AND ERNESTO POLLITT AND WILLIAM H. MUELLER \\ The University of Texas, School of Public Health, Houston, Texas 77025, USA
}

(Received 30 November 1982 - Accepted 15 November 1983)

\begin{abstract}
1. Effects of a feeding programme on maternal weight, triceps and subscapular skinfolds during pregnancy and lactation were assessed in a marginally undernourished population of rural Taiwan. Mothers participated during two pregnancy and lactation periods. At 3 weeks after the delivery of the first infant, one group of 114 mothers began consuming a nutrient-dense supplement (A), while another group of 111 received a placebo (B).

2. There was no significant $A-B$ difference in pregnancy weight gain $(A 7.52 \mathrm{~kg}, \mathrm{~B} 7.75 \mathrm{~kg}$ ) or in mean maternal weight, triceps or subscapular skinfolds at any time during pregnancy or lactation. Despite a general trend toward moderate weight loss during lactation, one-third of mothers in both groups gained weight. Highly significant increases in weight and skinfold thicknesses from one lactation period to the next characterized both groups.

3. The absence of demonstrable suppiement-effects on maternal anthropometry concomitant with increments in infant birth weight supports the notion that infants can benefit from maternal supplementation without changes in maternal nutritional status.
\end{abstract}

Extensive research efforts in the last two decades have been concerned with the effects of maternal nutritional status on the growth and development of offspring. The low birth weights of infants born to women who were pregnant during famine conditions (Antonov, 1947; Smith, 1947; Stein et al. 1975) and the beneficial effects of maternal nutritional supplementation on intra-uterine growth have demonstrated that a developing fetus is not immune to the nutritional status of its mother. For example, some nutritional interventions which had as their target pregnant women within populations with a high prevalence of undernutrition have shown relatively small but statistically demonstrable increases in birth weight, decreased incidence of low-birth-weight infants, and reduced infant mortality (Lechtig et al. 1975; Mora et al. 1979).

A working hypothesis of nutrition-intervention studies directed at pregnant and lactating women is that increased dietary intake in the mother results in improved fetal outcomes. Often, however, little attention is given to the effects of the increased intake on the women themselves. Specifically, there is a scarcity of information on changes in body measurements or body proportions among pregnant or lactating nutritionally supplemented women. Furthermore, the correlations that have been reported between nutritional supplementation and maternal weight gain have been weak at best. For example, in Colombia a statistically significant correlation between maternal supplementation and pregnancy weight gain was found only among women pregnant with male infants (Mora et al. 1979). In Guatemala, where women in a high-supplement group experienced a decreased incidence of low pregnancy weight gain (less than $0.5 \mathrm{~kg} /$ month), the correlation between supplement energy and monthly weight gain was only 0.214 (Lechtig et al. 1978).

A question raised by Lechtig et al. (1978) is whether maternal supplementation may have a beneficial effect on intra-uterine growth without having any demonstrable effect on the 
nutritional status of the mother. Benefits to the offspring resulting from maternal nutritional supplementation have already been demonstrated in the population to be examined here. For example, male infants whose mothers received a nutrient-dense supplement during pregnancy weighed $161 \mathrm{~g}$ more at birth than their male siblings born after previous, unsupplemented pregnancy (McDonald et al. 1981). There is also evidence that supplementation had an even greater effect on components of variation in infant measurements at birth. For example, supplementation interfered with the extent to which siblings resembled one another (particularly in Rohrer's index, weight/length ${ }^{3}$ ) at birth (Mueller \& Pollitt, 1982; Pollitt \& Mueller, 1982).

The purpose of the present paper is to examine the effects of a programme which provided a high-energy, protein-rich dietary supplement during pregnancy and lactation on body measurements of women thought to be nutritionally at risk. We wanted to see whether the supplement replenished or prevented exhaustion of maternal energy stores, measured by weight and skinfold thicknessess, during the stress of pregnancy and lactation, or whether previously described benefits to the offspring occurred without a change in maternal anthropometry.

\section{METHODS}

The study on which the present paper is based was carried out in Suilin Township, Taiwan, from 1967 to 1973 by the late Dr Bacon Chow of the Johns Hopkins School of Hygiene. Information on the effects of the supplement on birth weight, sibling-sibling anthropometric correlations, postnatal physical growth and behavioural development have already been reported (McDonald et al. 1981; Mueller \& Pollitt, 1982; Joos et al. 1983; Wohlleb et al. 1983). Since Dr Chow's original intention was to test the effects of a high-quality protein supplement during pregnancy on birth outcomes, a population with marginal protein intake was sought. No thought was given, however, to carrying out the intervention in a severely-malnourished population. The area chosen, Suilin Township, is an agricultural, economically distressed area of about $70 \mathrm{~km}^{2}$ located in West Central Taiwan. Subsistence foods include locally grown rice, peanuts (Arochis hypogaea) and sweet potatoes (Ipomoea batatas). A preliminary survey conducted in the Suilin area in 1965 indicated that daily protein intake from primarily vegetable sources was less than $40 \mathrm{~g}$, while energy intake was estimated to range from 6.68 to $8.35 \mathrm{MJ}(1600-2000 \mathrm{kcal}) / \mathrm{d}$. It should be emphasized that the preliminary survey did not examine the same individuals who later participated in the study. When home dietary intake was later measured regularly among the latter, average daily intake at meals was found to be closer to $5.02 \mathrm{MJ}(1200 \mathrm{kcal})$.

Women in fourteen of the twenty-four villages of Suilin Township were selected for the study if they met the following criteria (Blackwell et al. 1973): (1) married with at least one male child, (2) in the second or third trimester of pregnancy, (3) planning not to use contraceptives, (4) of low socio-economic status, (5) dietary intake of less than $40 \mathrm{~g}$ protein/d, (6) haemoglobin greater than $110 \mathrm{~g} / \mathrm{l}$, , (7) packed cell volume greater than 0.36 , (8) plasma protein greater than $55 \mathrm{~g} / 1$.

Original selection criteria also specified that the women should be 18-20 years of age, but included cases ranging from 19 to 30 years of age. Likewise, although selection criteria specified that packed cell volume values be greater than 0.36 , actual values during the later part of pregnancy ranged from 0.22 to 0.46 .

Subjects were randomly and blindly assigned to one of two treatment groups, both of which received $370 \mathrm{ml}$ unmarked cans of chocolate-flavoured liquid twice daily. Group A received a supplement which contained $20 \mathrm{~g}$ milk protein, $1.67 \mathrm{MJ}(400 \mathrm{kcal})$, vitamins and minerals. Group B received a so-called placebo which contained no protein and, for most of the study, less than $0.02 \mathrm{MJ}$ ( $4 \mathrm{kcal}$ ) per can (see Tables 1 and 2). In 1971, 4 years after the study began, it was necessary to alter the composition of the supplement due to the 
Table 1. Nutrient content of each $370 \mathrm{ml}$ can of nutrient-dense supplement $(A)$ or placebo $(B)$

\begin{tabular}{lccc}
\hline & $\mathrm{A}$ & & \multicolumn{2}{c}{$\mathrm{B}^{*}$} \\
\cline { 3 - 4 } & & Before June 1971 & After June 1971 \\
\hline Protein (g) & 20 & Trace & Trace \\
Fat (g) & $13 \cdot 3$ & Trace & Trace \\
Carbohydrate (g) & 50 & Trace & 10 \\
Energy & & & 0.0125 \\
$\quad$ MJ & 1.67 & 3 & 0.18 \\
kcal & 400 & & 43 \\
\hline \hline
\end{tabular}

* After June 1971 the placebo was sweetened with sucrose rather than cyclamates due to a ban on cyclamates in the USA. 76\% Of group B second-study infants were born before June $1971 ; 52 \%$ were tested before June 1971.

Table 2. Vitamin and mineral content in one $370 \mathrm{ml}$ can of nutrient-dense supplement $A$

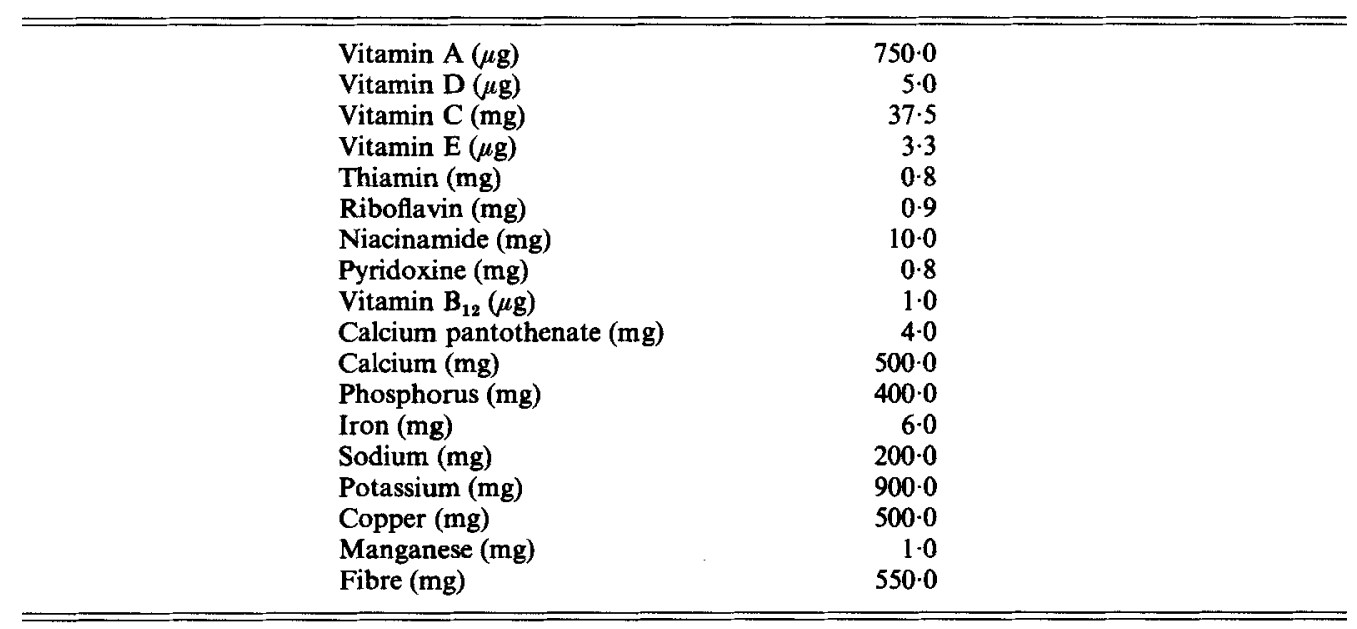

ban on cyclamates in the US where the product was manufactured by Mead Johnson. Supplement B, shipped to Taiwan after June 1971, was sweetened with sucrose rather than cyclamates and contained about $0 \cdot 167 \mathrm{MJ}(40 \mathrm{kcal})$ per can. A most conservative estimate is that $24 \%$ of the second-study group-B infants were born after mothers began to consume the reformulated supplement. Neither the subjects consuming the supplement nor the nurses who oversaw its delivery and recorded its consumption twice daily knew which supplement was being consumed.

Home dietary intake was determined once during each trimester of the second-study pregnancy and lactation periods. Nurses visited homes and weighed the mother's portion of food to be consumed at each meal. Duplicate samples were taken for laboratory analysis of carbohydrate, fat and protein. No assessment of intermeal food consumption was made. Values are available on 113-173 women in each trimester. We have no information on why unequal numbers of women were surveyed in each trimester.

In most studies of maternal nutrition supplementation, each mother completes one pregnancy and lactation period but, in the present study, mothers were followed during two consecutive pregnancy and lactation periods. The supplement was offered beginning 3 weeks 
Table 3. Marginally nourished Taiwanese women receiving a nutrient-dense supplement $(A)$ or placebo (B) compared with US National Center for Health Statistics (NCHS, 1966) weight-for-height standards of women aged 24-35

\begin{tabular}{|c|c|c|c|c|c|c|}
\hline \multirow{2}{*}{$\begin{array}{l}\text { Group... } \\
\text { Percentile }\end{array}$} & \multicolumn{2}{|c|}{ Al } & \multicolumn{2}{|c|}{ B1 } & \multicolumn{2}{|c|}{$\mathrm{A} 1+\mathrm{B} 1$} \\
\hline & $n$ & $\%$ & $n$ & $\%$ & $n$ & $\%$ \\
\hline \multicolumn{7}{|c|}{$\begin{array}{l}\text { Maternal weight-for-height } 1 \text { month after } \\
\text { the birth of the first-study infants }\end{array}$} \\
\hline 50th or above & 10 & 9 & 12 & 11 & 22 & 10 \\
\hline 10 th to 50 th & 80 & 73 & 67 & 61 & 147 & 67 \\
\hline Below loth & 20 & 18 & 30 & 28 & 50 & 23 \\
\hline Group... & \multicolumn{2}{|c|}{ A2 } & \multicolumn{2}{|c|}{ B2 } & \multicolumn{2}{|c|}{$\mathrm{A} 2+\mathrm{B} 2$} \\
\hline Percentile & $n$ & $\%$ & $n$ & $\%$ & $n$ & $\%$ \\
\hline \multicolumn{7}{|c|}{$\begin{array}{l}\text { Maternal weight-for-height } 1 \text { month after } \\
\text { the birth of the second-study infants }\end{array}$} \\
\hline 50th or above & 18 & 22 & 9 & 11 & 27 & 17 \\
\hline 10 th to 50 th & 52 & 63 & 61 & 76 & 113 & 70 \\
\hline Below 10th & 12 & 15 & 10 & 13 & 22 & 13 \\
\hline
\end{tabular}

$$
\begin{aligned}
& \text { Chi-square test of distributions: } \\
& \text { A1-A2 } \chi^{2}=6 \cdot 21, P<0.05 \\
& \text { B1-B2 } \chi^{2}=6 \cdot 52, P<0.05 \\
&(\mathrm{~A} 1+\mathrm{B} 1)-(\mathrm{A} 2+\mathrm{B} 2) \chi^{2}=7 \cdot 27, P<0.05
\end{aligned}
$$

after the birth of the first-study infant and continued until 15 months after the birth of the second-study infant. Thus it is possible to compare two pregnancy outcomes (one treated, one untreated) in the same mother (intragroup A1-A2 or B1-B2 comparisons) and to compare the effects of supplement and placebo on both maternal and infant outcomes (intergroup A-B differences).

The sample analysed in the present paper consisted of 225 mothers, 114 in group A and 111 in group B, who gave birth to two infants in the period covered by the study ( 6.5 years). Since the mothers were recruited into the study during the third trimester of pregnancy $(\mathrm{P} 1)$, no baseline or pre-pregnant values are available. Mothers were measured at least once before the delivery of the first infant, then at regular intervals throughout both lactation periods (L1 and L2) and the second pregnancy (P2). Measurements taken included height, weight and triceps and subscapular skinfold thicknesses. There were no statistically significant intergroup differences in mean maternal height (m; A 1.551, B 1.544), age (years; A 26.6, B 26.1), parity (A 2.5, B 2.5), education level (years; A 1-2, B 1.2) or birth interval (d; A 753, B 764, range 392-1445).

\section{RESULTS}

\section{Over-all nutritional status of the population}

Nutritional status of the population may be assessed by the traditional method of comparison with US National Center for Health Statistics (NCHS) standards of weightfor-height (NCHS, 1966) and by examining pregnancy weight gains relative to those found in other populations. Values from the NCHS are widely accepted as the best-available standards for adults and are useful in taking height into considerations. Table 3 shows that, 1 month after the birth of the first-study infant (and only 1 week after supplementation was begun), few Suilin mothers fell above the 50th percentile of NCHS (1966) weight- 
for-height standards for women aged $24-35$ years, while $25 \%$ of the population fell below the 10th percentile. At the same time relative to the birth of the second infant, the distribution of maternal weights-for-height was significantly different in both $A$ and $B$ groups. The difference was due to a decrease in the number of women below the 10 th percentile and an increase in the number above the 50th, indicating an over-all improvement in nutritional status with time.

Suilin mothers gained $15-16 \%$ of pre-pregnant body-weight during the second pregnancy. This may be contrasted with gains of $13 \%$ from the 12 th week of pregnancy to delivery in a malnourished Indian population (Venkatachalam et al. 1960) and total gains representing about $18 \%$ of pre-pregnant body-weight in well-nourished British mothers with unrestricted dietary intake (Taggert et al. 1967).

Energy intake calculated from the home-food surveys and mean daily supplement consumption are presented in Table 4 . Intergroup comparisons revealed no significant $\mathbf{A}-\mathbf{B}$ difference in home-food intake during pregnancy. Group B mothers consumed significantly more energy from home food 0-2 and 6-8 months post-partum, but not during any other time interval. A-B differences in energy from supplement and supplement plus home food were significant during all sampling periods. In both $A$ and $B$ groups, supplement consumption was significantly higher during the lactation period (birth-15 months) than during pregnancy. Energy intakes from home food were likewise greater during lactation. Comparisons of each lactation trimester with the last trimester of pregnancy revealed significant differences in group B throughout lactation, and in group A beginning at the fifth post-partum month. Estimates of home-food intake should be treated conservatively. Because the measurements focused on meals, total intake may have been underestimated.

\section{Pregnancy}

Mean maternal weights and triceps and subscapular skinfolds measured within $30 \mathrm{~d}$ before delivery are presented in Table 5 . For both study pregnancies (treated and untreated), there was no statistically significant $\mathrm{A}-\mathrm{B}$ difference in any of these three body measurements.

In contrast, intragroup (A1-A2 and B1-B2) differences in mean maternal weight were highly significant. Both group A and B mothers weighed more before the delivery of the second-study infant than they did at the same time relative to the delivery of the first. Pre-delivery skinfold thicknesses did not differ from one pregnancy to the next.

Analyses of weight gain are necessarily confined to intergroup comparisons for $\mathrm{P} 2$, since no pre- or early pregnancy value is available for P1. Pregnancy weight gain was calculated as the difference between the last measurement taken before delivery and the last pre-pregnant weight. Weight gain and changes in skinfold thickness by trimester and through the entire pregnancy are presented in Table 6. Mothers were included in the summaries only if measurements were available at the beginning and end of each trimester. There was no A-B difference in pregnancy weight gain ( $\mathrm{kg} ; \mathrm{A} 7 \cdot 52$ (SE 2.8), range 1-14.8; B 7.75 (SE 2.5), range 2-14.5).

Skinfold measurements showed a wide range of variability within both groups during P2 but no consistent or significant intergroup difference in either triceps or subscapular skinfolds was apparent. No differences in the changes in maternal anthropometry by the gender of the fetus carried were apparent either within or between supplement groups. Over-all, we see that within-group changes in maternal anthropometry from one study period to the next exceeded intergroup differences associated with the supplement.

\section{Lactation}

Weight and skinfold thickness were measured at regular intervals throughout both lactation periods. Mean values across time-periods are presented in Figs 1-3. Over-all patterns of 
Linda S. Adair, E. Pollitt and W. H. Mueller

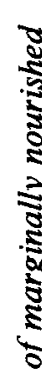

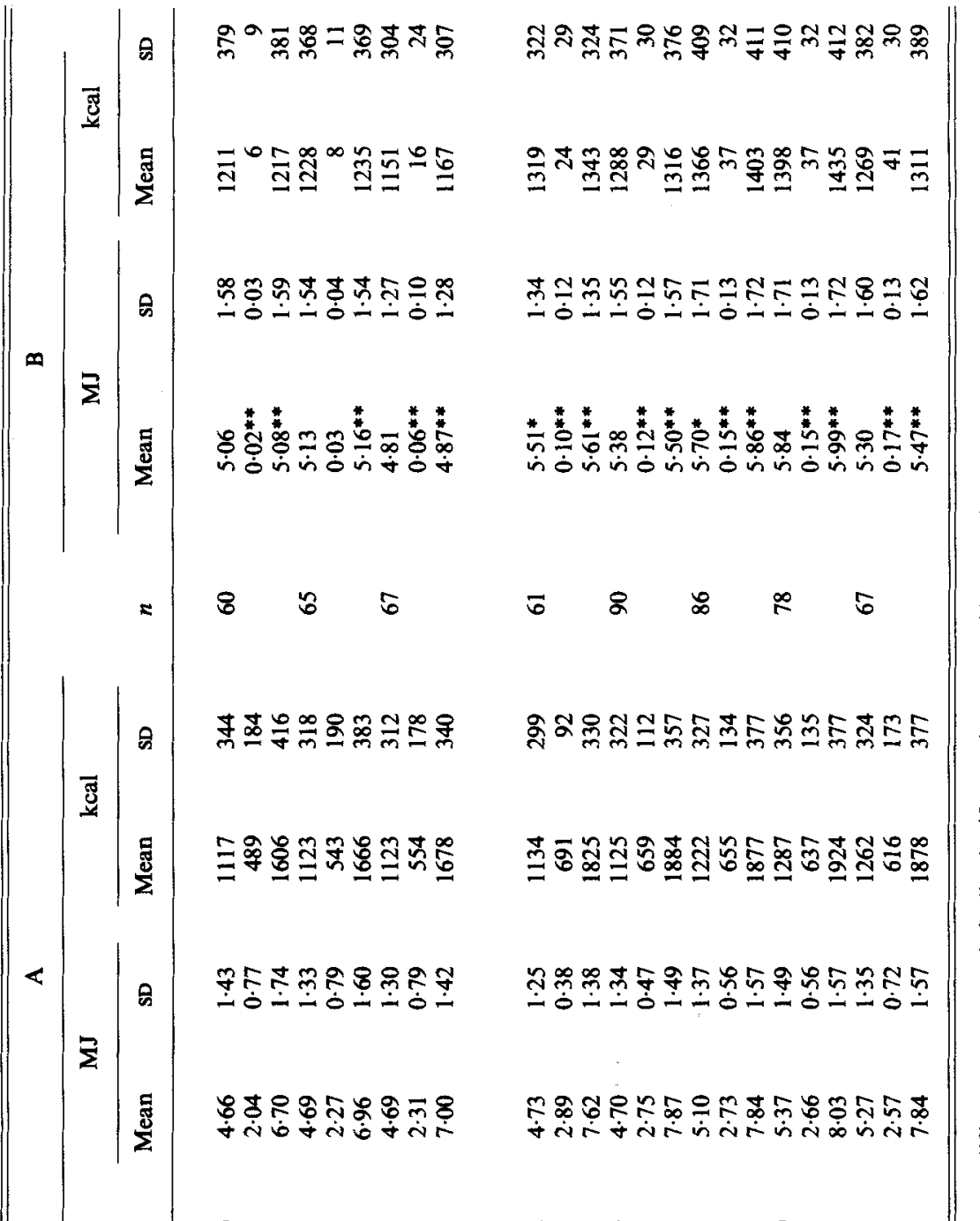

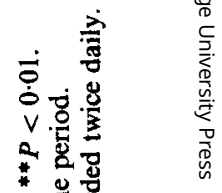

จิ

2

ड़े

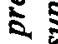

है क्ष

$+\frac{1}{3}$

密

골

क

8

t:

ปั

$s$

空

$=$

850

$\approx \approx \infty \approx n$ 官要兽

$\checkmark-7$

ใ.

芦

题要

焉

要

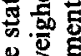

政

\%

怤造

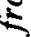

จั

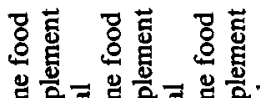

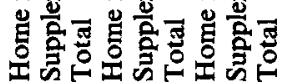

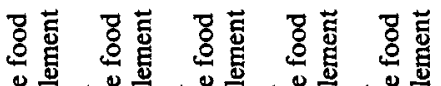

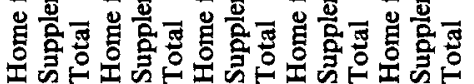

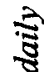

క

$\Sigma$

$\dot{+}$

苛

总

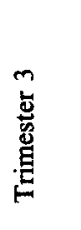

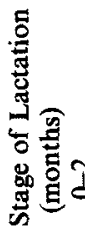

$m \infty=\frac{n}{1}$ 


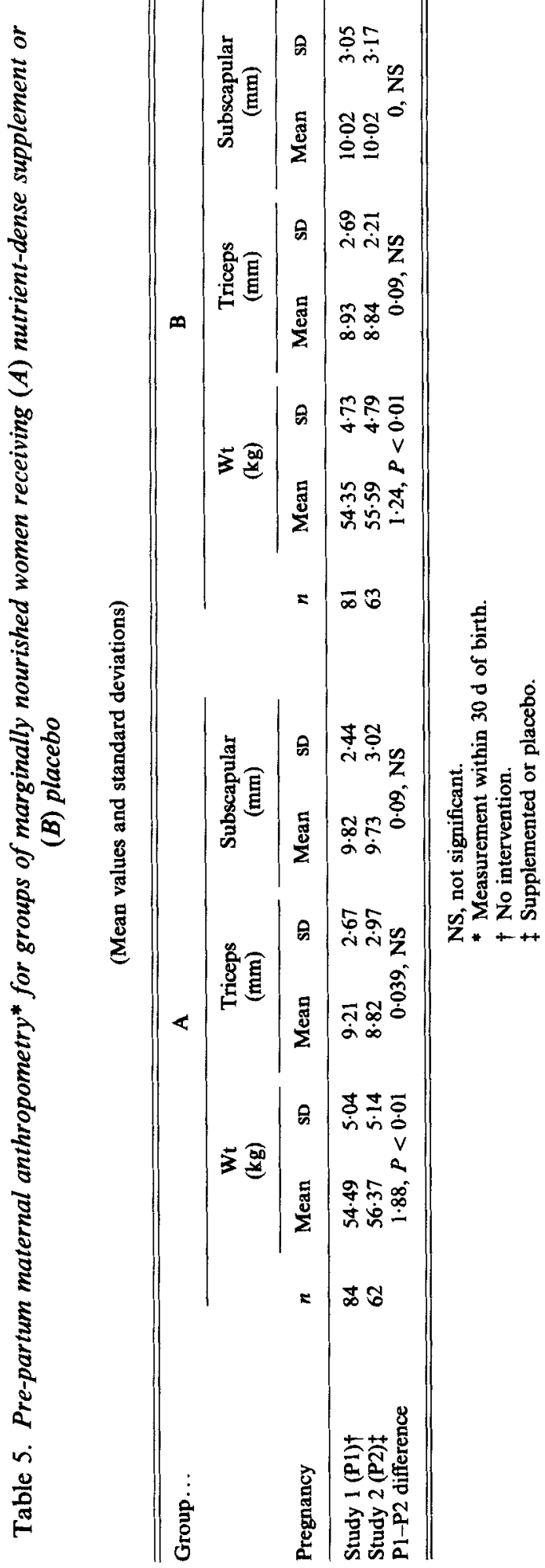


Table 6. Anthropometric changes during the second-study pregnancy of groups of marginally nourished women receiving $(A)$ nutrient-dense supplement or $(B)$ placebo

(Mean values and standard deviations)

\begin{tabular}{|c|c|c|c|c|c|c|}
\hline \multirow[t]{2}{*}{ Group... } & \multicolumn{3}{|c|}{ A } & \multicolumn{3}{|c|}{ B } \\
\hline & $n$ & Mean & SD & $n$ & Mean & SD \\
\hline \multicolumn{7}{|l|}{ Wt $(\mathbf{k g})$} \\
\hline First trimester & 70 & 0.53 & $2 \cdot 63$ & 32 & 1.44 & $3 \cdot 14$ \\
\hline Second trimester & 34 & 4.46 & $2 \cdot 37$ & 25 & $4 \cdot 26$ & $2 \cdot 12$ \\
\hline Third trimester & 25 & $2 \cdot 08$ & 1.95 & 22 & $2 \cdot 36$ & $1 \cdot 28$ \\
\hline Total gain & 62 & $7 \cdot 52$ & $2 \cdot 77$ & 63 & $7 \cdot 75$ & $2 \cdot 51$ \\
\hline Percentage of pre-pregnant wt & & $15 \cdot 3$ & & & 16.0 & \\
\hline \multicolumn{7}{|l|}{ Triceps (mm) } \\
\hline First trimester & 42 & $-0 \cdot 11$ & $2 \cdot 09$ & 32 & $0 \cdot 37$ & $2 \cdot 22$ \\
\hline Second trimester & 34 & $-0 \cdot 17$ & $1 \cdot 54$ & 25 & $0 \cdot 31$ & 1.87 \\
\hline Third trimester & 25 & $-0 \cdot 28$ & $1 \cdot 70$ & 22 & -0.87 & $1 \cdot 53$ \\
\hline Over-all change & 62 & -0.02 & $2 \cdot 48$ & 63 & 0.18 & $2 \cdot 03$ \\
\hline \multicolumn{7}{|l|}{ Subscapular (mm) } \\
\hline First trimester & 42 & $0 \cdot 17$ & 2.69 & 32 & 0.92 & $2 \cdot 56$ \\
\hline Second trimester & 34 & 1.02 & $2 \cdot 35$ & 25 & 0.87 & $2 \cdot 10$ \\
\hline Third trimester & 25 & -0.65 & 1.58 & 22 & -0.71 & $1 \cdot 15$ \\
\hline Over-all change & 62 & 0.77 & 2.75 & 63 & 0.79 & 2.65 \\
\hline
\end{tabular}

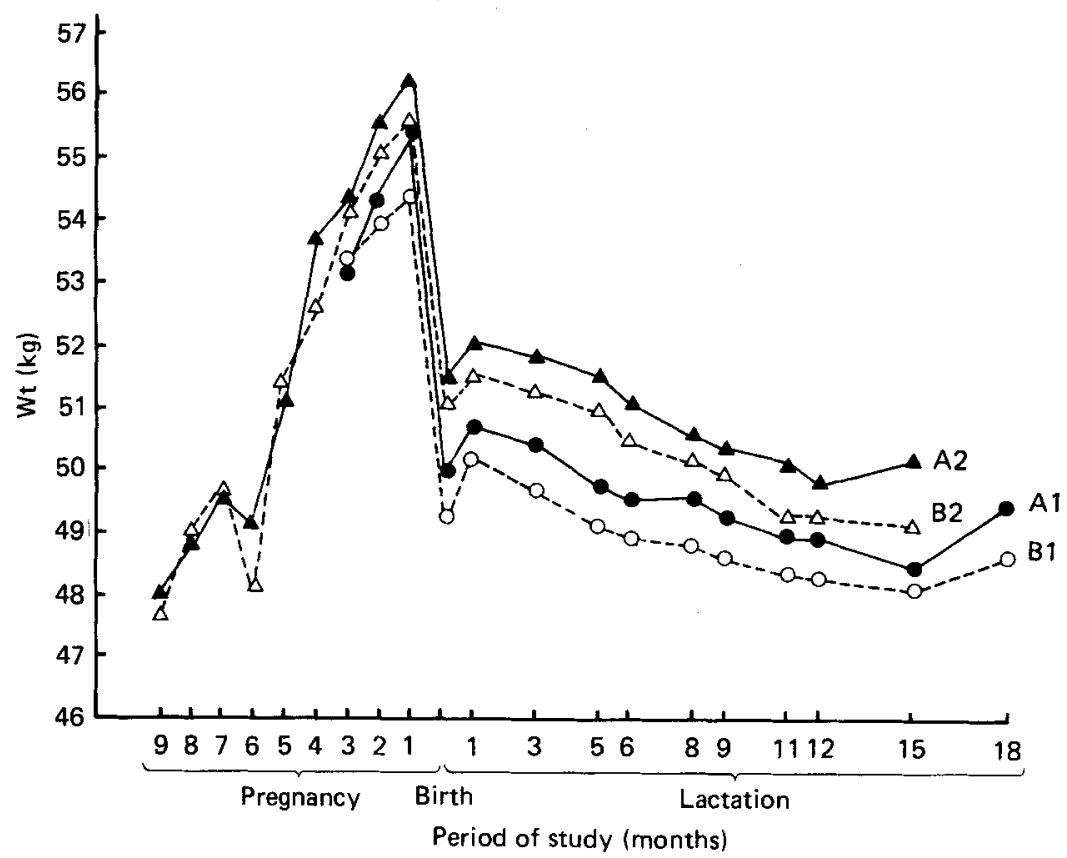

Fig. 1. Mean maternal weights during two pregnancy and lactation periods for groups of marginally undernourished women receiving (A) nutrient-dense supplement or (B) placebo. 


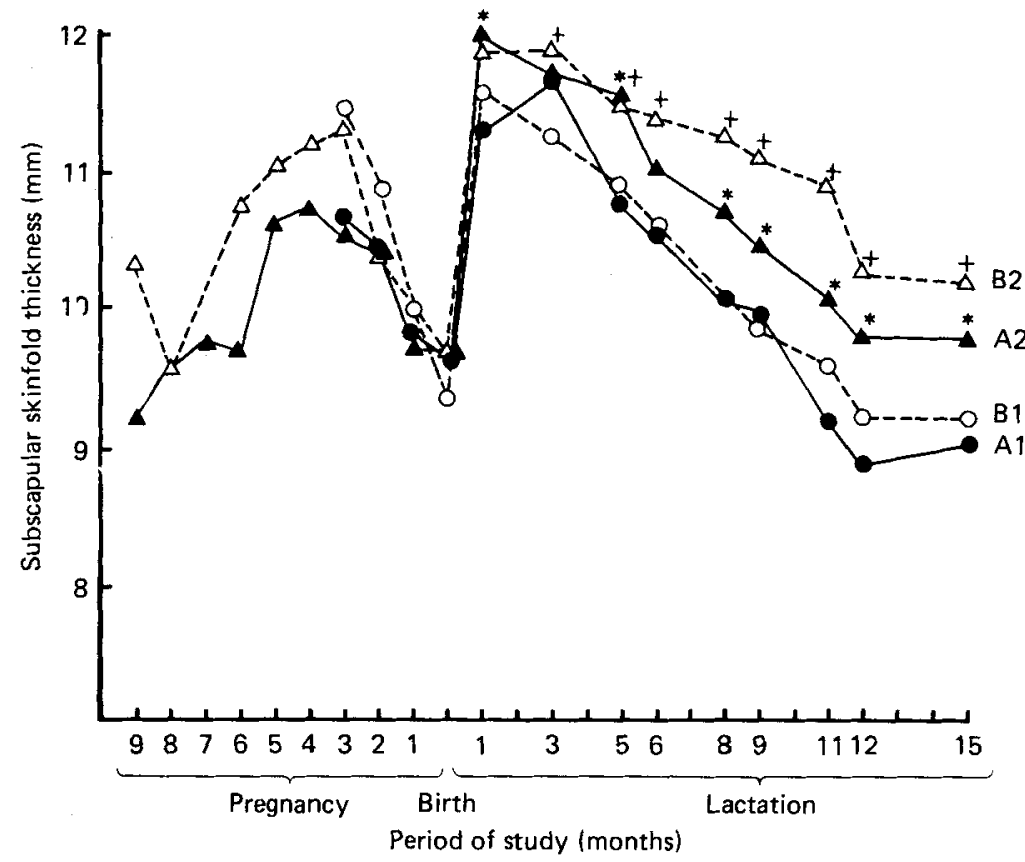

Fig. 2. Mean maternal subscapular skinfold thicknesses during two pregnancy and lactation periods for groups it marginally undernourished women receiving (A) nutrient-dense supplement or (B) placebo. A1-A2 $\left(^{*}\right)$ and B1-B2 $(+)$ differences were statistically significant $(P<0.05)$.

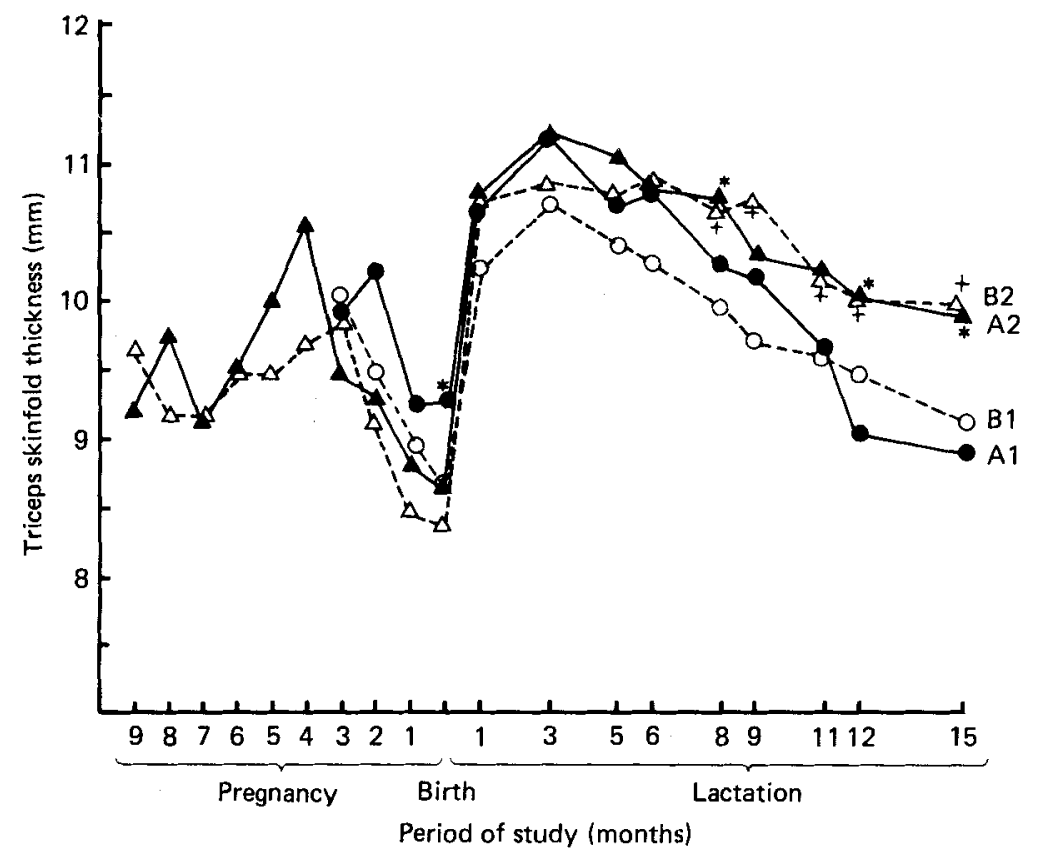

Fig. 3. Mean maternal triceps skinfold thicknesses during two pregnancy and lactation periods for groups of marginally undernourished women receiving (A) nutrient-dense supplement or (B) placebo. A1-A2 $\left(^{*}\right)$ and B1-B2 $(+)$ differences were statistically significant $(P<0.05)$. 

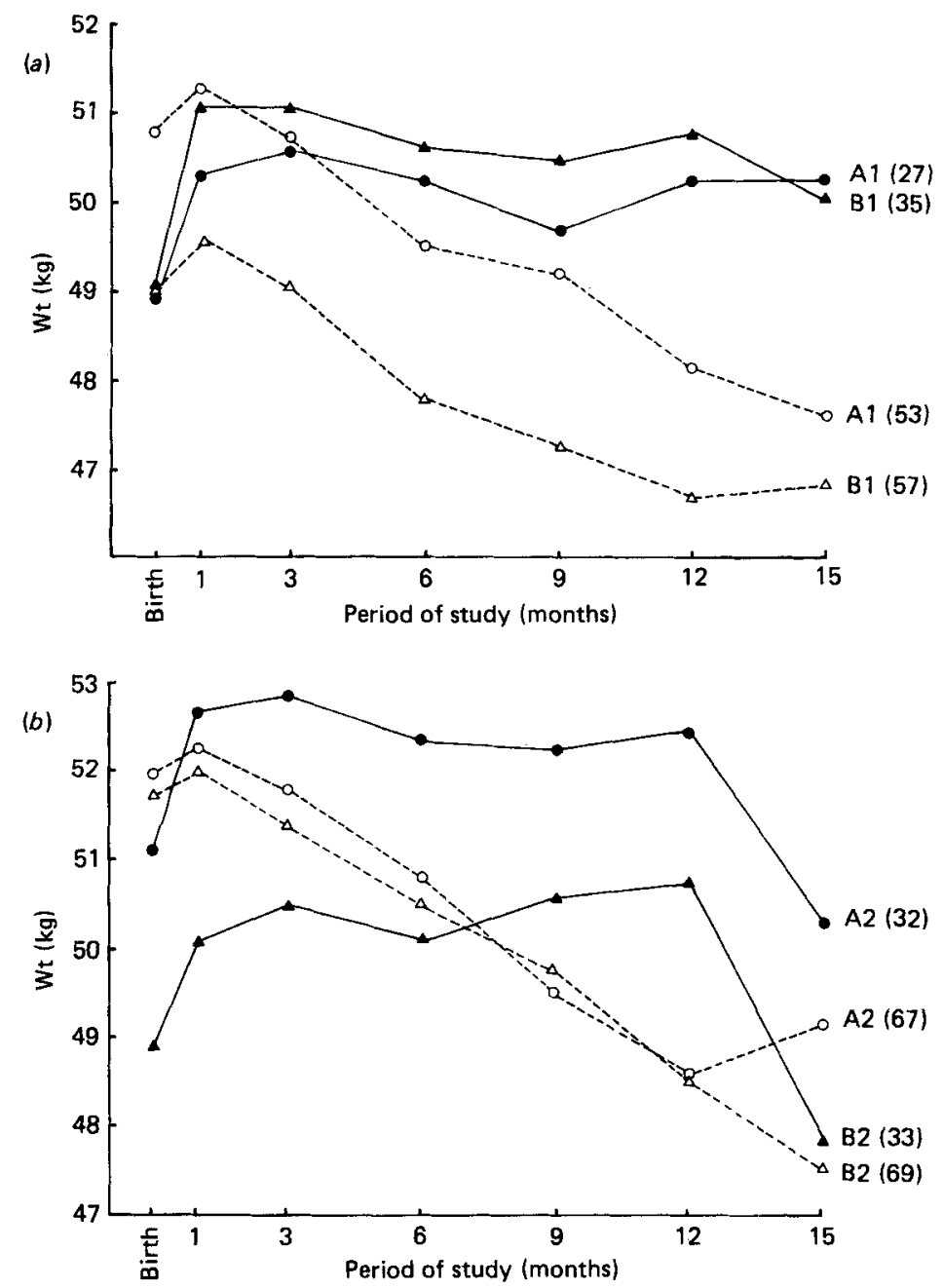

Fig. 4. Mean maternal weights during lactation periods $(a) \mathrm{L} 1$ and $(b) \mathrm{L} 2$ for groups of marginally, undernourished women receiving (A) nutrient-dense supplement or (B) placebo. Mean weights of mothers who lost weight (----) during lactation are compared with those who gained weight $(-$ ). Number of mothers in parentheses.

anthropometric change are remarkably similar in groups $\mathrm{A}$ and $\mathrm{B}$ and during both lactation periods ( $\mathrm{L} 1$ and $\mathrm{L} 2$ ). Mothers gained weight and increased skinfold thicknesses from immediately after delivery to the end of the first post-partum month, then lost weight and skinfold thickness during the remainder of the lactation period.

A consistent intergroup difference of $0.5-0.7 \mathrm{~kg}$ in mean maternal weight occurred throughout L1 and L2. Comparison of lines derived by linear regression of all maternal weight values for each group by month at $3,6,9,12$ and 15 months, however, revealed no significant A-B differences in slope or intercept, nor were differences in mean maternal weight of statistical significance at any single time during lactation. Although mean maternal weight values showed a decline during lactation, there were mothers in groups $\mathrm{A}$ and $\mathrm{B}$ who gained weight during lactation periods $\mathrm{L} 1$ and L2. Accordingly, weight-loss and weight-gain groups were defined and based on the net change in weight from just after delivery to 12 months post-partum. Although the usual period of lactation is 15 months, 
the 12-month measurement was chosen to avoid the confounding effects of weaning between 12 and 15 months.

A $t$ test comparison of mean maternal weights for weight-loss and weight-gain groups (see Fig. 4) revealed no significant $\mathbf{A}-\mathbf{B}$ difference between mothers who gained weight during lactation. We did find significant $\mathbf{A}-\mathbf{B}$ differences in the weight-loss groups at 3 $(P=0.032), 6(P=0.030)$ and $9(P=0.016)$ months after delivery, but these differences were due to the higher initial weight $(P=0.031)$ of the group A weight-gain mothers before supplementation. During L2, we found parallel changes in A and B weight-loss and A and B weight-gain groups, but in this case there were significant A-B differences in the weight-gain groups at $1(P=0.027), 3(P=0.040), 11(P=0.049)$ and $15(P<0.01)$ months. Again, these differences were due to the significantly higher initial weight of the A weight-gain group $(P=0.047)$ rather than to a systematic effect of supplementation.

Further evidence for the lack of a supplement effect on maternal body dimensions was shown by the absence of any significant differences in mean skinfold thicknesses or change in skinfold thicknesses at any time during $\mathrm{L} 1$ or $\mathrm{L} 2$.

Intragroup (A1-A2 and B1-B2) differences in mean maternal weight were highly significant $(P<0.01)$ at all times measured. Mothers in groups A and B weighed approximately $1.2-1.6 \mathrm{~kg}$ more during $\mathrm{L} 2$ compared with $\mathrm{L} 1$. Intragroup differences of $0.5-0.6 \mathrm{~mm}$ in triceps and subscapular skinfolds were significant at most time-periods during the latter part of lactation (see Figs 2 and 3).

\section{DISCUSSION}

Analysis of mean maternal weight and skinfold thicknesses throughout pregnancy and lactation in a population initially judged to be marginally undernourished revealed no statistically significant effect of a maternal feeding programme which provided supplemental energy and high-quality protein. Furthermore, weight changes during lactation seemed to reflect the body-weight at the beginning of lactation rather than any effect of the programme.

Based on comparisons with NCHS (1966) weight-for-height standards and pregnancy weight gains of well-nourished British women (Taggert et al. 1967) the initial judgement of the population as marginally malnourished appears to be borne out. However, the fact that a significant portion of the Suilin population showed no evidence of energy deficit during lactation, regardless of supplement group, suggests that weight gains during pregnancy and over-all maternal body size were near optimum for that population. Moreover, dietary findings indicate that women increased both food and supplement intake during lactation compared with intake during the last trimester of pregnancy. This would suggest that effective homeostatic or energy balance mechanisms were in operation, and that low intakes observed during pregnancy were not due entirely to limitations in food availability. Furthermore, pregnancy outcomes were favourable. Mean birth weights of first- and second-study infants were in excess of $3 \mathrm{~kg}$, and the incidence of low birth weight $(<2500 \mathrm{~g})$ was only about $6 \%$. Most mothers may thus have maintained an appropriate energy balance, compromising neither their own health status nor the health status of their developing infants. Benefits to the offspring, such as those mentioned previously, could accrue without significant changes in maternal body dimensions.

Other observations demonstrating the absence of severe energy deficits in the population include the following: regardless of supplement group, maternal skinfold thicknesses were greater at the end of L2 than early in P2, and maternal weights and skinfolds were greater at all times in L2 compared with L1. This fits well with observations from the Gambia, where mothers with low energy intake maintained body-weight well during lactation apart from seasonal changes experienced by all women in the area (Thomson et al. 1966; Prentice et al. 1980). In contrast, information from an unquestionably malnourished population in 
India showed a decrease in maternal weight and skinfold thicknesses with parity, indicating a long-term energy deficit through the childbearing years (Venkatachalam et al. 1960). Thus supplementation may fail to produce changes in maternal body composition when, despite low energy intakes, women are already maintaining energy balance.

Nutritional supplementation may have benefited mothers in ways not measured in the present study. For example, supplementation may have resulted in increased activity levels. Since this is an agricultural population where women's labour is important, any increases in energy intake may have enabled pregnant and lactating women to maintain normal work output. This would be consistent with statements made by Gambian women who experienced no improvement in lactation performance with nutritional supplementation, but stated that they had more energy for farming (Prentice et al. 1980).

Finally, it is not possible to quantify the extent to which the feeding programme actually supplemented the diets of Suilin mothers. We have no information on intermeal food consumption or on pre-intervention dietary intake in the study population. Some evidence for dietary substitution is provided by higher home-food intakes in group B, 0-2 and 6-8 months post-partum, but it is perhaps more striking to note the absence of home-food intake differences at all other times during pregnancy and lactation. Furthermore, the range of energy intakes found in Suilin mothers is close to that reported for other rural, pregnant Taiwanese women; for example, 6.79 MJ (1668 kcal)/d in Taichung County (Kao, 1980). Despite our inability to quantify the actual level of supplementation, there is excellent evidence of its effectiveness in the benefits to offspring of group A mothers.

Over-all, the results of the Taiwan study are consistent with those of other maternal supplementation studies which had as their target undernourished women (Lechtig et al. 1978; Mora et al. 1979), where supplement effects on maternal body dimensions are small or negligible, but infants, particularly those most at risk, may benefit.

Dr R. Quentin Blackwell was a principal co-investigator of the study during the period of data collection. At that time he was a staff member at the United States Medical Research Unit no. 2 in Taipei, Taiwan. His contribution in making the present study possible is gratefully acknowledged.

The authors thank the University of Texas School of Public Health for provision of computer time, and Gay Robertson and the staff of the Word Processing Center for manuscript preparation. The Nestle Coordination Center for Nutrition, Washington DC, and the Ford Foundation supported in part the data analysis for the present paper.

\section{REFERENCES}

Antonov, A. M. (1947). Journal of Pediatrics 30, 250-259.

Blackwell, R. Q., Chow, B., Chin, K., Blackwell, B. N. \& Hsu, S. C. (1973). Nutrition Reports International 7, $517-532$.

Joos, S. K., Pollitt, E., Mueller, W. H. \& Albright, D. L. (1983). Child Development 54, 669-676.

Kao, M. D. (1980). Journal of the Chinese Nutrition Society 5, 41-49.

Lechtig, A., Delgado, H., Lasky, R. E., Yarbrough, C., Klein, R. E., Habicht, J-P. \& Behar, M. (1975). American Journal of Diseases of Childhood 129, 129, $434-437$.

Lechtig, A., Martorell, R., Delgado, H., Yarbrough, C. \& Klein, R. E. (1978). Journal of Tropical Pediatrics 12, 217-222.

McDonald, E. C., Pollitt, E., Hsueh, A. M. \& Sherwyn, R. (1981). American Journal of Clinical Nutrition 34, 2133-2144.

Mora, J. O., de Paredes, B., Wagner, L., de Navarro, L., Suescun, J., Christiansen, N. \& Herrera, M. G. (1979). American Journal of Clinical Nutrition 32, 455-462.

Mueller, W. H. \& Pollitt, E. (1982). Human Biology 54, 544-568.

National Center for Health Statistics (1966). Vital and Health Statistics, series 11, no. 14.

Pollitt, E. \& Mueller, W. H. (1982). Early Human Development 7, 251-256.

Prentice, A. M., Whitehead, R. G., Roberts, S. B., Paul, A. A., Watkinson, M., Prentice, A. \& Watkinson, A. A. (1980). Lancet i, 886-888. 
Smith, C. A. (1947). American Journal of Obstetrics and Gynecology 55, 599-608.

Stein, Z., Susser, M., Saenger, G. \& Marolla, F. (1975). Famine and Human Development. New York, N.Y.: Oxford University Press.

Taggert, N. R., Holiday, R. M., Billewicz, W. Z., Hytten, F. E. \& Thomson, A. M. (1967). British Journal of Nutrition 21, 439-451.

Thomson, A. M., Billewicz, W. Z., Thompson, B. A. \& McGregor, A. (1966). Journal of Obstetrics and Gynecology of the British Commonwealth 73, 724-733.

Venkatachalam, P. S., Shankar, K. \& Gopalan, C. (1960). Indian Journal of Medical Research 48, $511-517$.

Wohlleb, J. C., Pollitt, E., Mueller, W. H. \& Bigelow, R. (1983). Early Human Development 9, $79-91$. 